\title{
Jaring Laba-Laba, Interaksi-Interkoneksi Universitas
Islam Negeri Sunan Kalijaga Yogyakarta
}

\author{
Mohamad Yamin ${ }^{1}$, Nanat Fatah Natsir ${ }^{2}$, Erni Haryanti ${ }^{3}$ \\ 1,2,3Universitas Islam Negeri Sunan Gunung Djati Bandung, Indonesia \\ E-mail:mohamadyamin32@gmail.com,nanatfatahnatsir@uinsgd.ac.id,erni hk@uinsgd.ac.id
}

\begin{abstract}
Article Info
Abstract

Article History

Received: 2021-11-20

Revised: 2021-12-15

Published: 2022-01-14

This study describes the spider web, the interactions of the State Islamic University of Sunan Kalidjaga Yogyakarta. The method used in this study uses a library research method. The results of this study indicate that the development of Islamic studies in Indonesia began with the langgar system, the pesantren system, and the royal education system. Then in the 20th century, educational institutions began to appear in

Keywords: Integration;

Interconnection; Islamic Studies;

Islamic Education;

Islamic Religious;

College. the form of madrasas or schools managed by Islamic organizations. Along with the development of Islamic education from ancient times to the present, the facts show that most Islamic universities still follow the classical scientific platform which is dominated by al-ulum al-syar'i. Criticism after criticism has sprung up because so far the Islamic sciences that have developed have only been fragmentary in nature and have not had any connection with contemporary issues. Meanwhile, in the 21st century, everything is dominated by science (especially science). This research is in the form of a meta description regarding the implementation of the integrativeinterconnective paradigm in Islamic education at Islamic universities which had already been developed by UIN Sunan Kalijaga Yogyakarta. The results of the development of the integrative-interconnective paradigm at UIN Sunan Kalijaga Yogyakarta can be seen from the following aspects, such as in academic guidelines, sarpras, religious laboratories, science laboratories and others.
\end{abstract}

\begin{tabular}{l}
\hline Artikel Info \\
\hline Sejarah Artikel \\
Diterima: $2021-11-20$ \\
Direvisi: 2021-12-15 \\
Dipublikasi: $2022-01-14$
\end{tabular}

Kata kunci: Integrasi; Interkoneksi; Studi Islam; Pendidikan Islam; Perguruan Tinggi; Agama Islam.

\begin{abstract}
Abstrak
Penelitian ini menjelaskan tentang jaring laba-laba, interaksi-interkoneksi Universitas Islam Negeri Sunan Kalidjaga Yogyakarta. Metode yang digunakan dalam kajian ini menggunakan metode atau pendekatan kepustakaan (library research), Hasil penelitian ini menunjukkan bahwa perkembangan Studi Islam di Indonesia dimulai dengan sistem langgar, sistem pesantren, dan sistem pendidikan kerajaan. Kemudian di abad ke-20 mulai muncul lembaga pendidikan berupa madrasah atau sekolah yang dikelola oleh organisasi Islam. Seiring perkembangan Pendidikan Islam dari zaman dulu hingga sekarang, fakta menunjukkan bahwa sebagian besar perguruan tinggi Islam masih mengikuti platform keilmuwan klasik yang didominasi al-ulum al-syar'i. Kritik demi kritik bermunculan karena selama ini ilmu-ilmu keislaman yang berkembang hanya bersifat fragmenteris dan belum memiliki keterkaitan dengan isuisu kekinian. Sementara di abad ke-21 ini segala sesuatunya banyak didominasi oleh ilmu pengetahuan (khususnya sains). Penelitian ini berupa meta deskripsi mengenai implementasi paradigm integratif-interkonektif dalam pendidikan Islam di Perguruan Tinggi Islam yang sudah lebih dulu dikembangkan oleh UIN Sunan Kalijaga Yogyakarta. Hasil dari pengembangan paradigma integratif-interkonektif di UIN Sunan Kalijaga Yogyakarta dapat dilihat dari beberapa aspek berikut, seperti dalam pedoman akademik, sarpras, laboratorium agama, laboratorium sains dan lain-lain.
\end{abstract}

\section{PENDAHULUAN}

Perkembangan lembaga Pendidikan Islam di Indonesia merupakan perjalanan panjang. Menurut (Na'im, 2021) bahwa menilik perkembangan studi Islam di Indonesia, mula-mula lembaga pendidikan Islam menggunakan sistem langgar, disusul dengan sistem pesantren, lalu kemudian pendidikan di kerajaan-kerajaan Islam, seperti kerajaan Perlak di Selat Malaka berupa Majlis Ta'lim Tinggi, kerajaan Aceh Darussalam berupa Balai Seutia Humaha, Balai Seutia Ulama, dan Balai Jama'ah Himpunan Ulama. Barulah mulai abad ke-20 muncul madrasah dan sekolah model Belanda yang dikelola oleh organisasi Islam, seperti Muhamadiyyah, Nahdatul Ulama, dan lainnya, cikal bakal Perguruan Tinggi Islam tidak terlepas dari gagasan-gagasan umat Islam sejak zaman colonial (Arifudin, 2021). Gagasan dari Dr. Satiman Wirjosandjojo yang termaktub dalam Majalah Pedoman Masjarakat Nomor 15 tahun IV (1938), menjadi salah satu gagasan yang mendapat respon positif dari para tokoh muslim. 
Dan hasilnya didirikanlah Perguruan Tinggi Islam di Solo, tapi sayangnya perguruan ini hanya bertahan sampai tahun 1941 .

Kemudian pada tanggal 8 juli 1945 dibuka secara resmi Sekolah Tinggi Islam (STI) di Jakarta yang saat ini lebih dikenal dengan Universitas Islam Indonesia (UII) Yogyakarta. Fakultas Agama UII menjadi cikal bakal Perguruan Tinggi Agama Islam Negeri (PTAIN) pada tahun 1950, saat UII mendapat tawaran dari pemerintah untuk dinegerikan (Nasution, 2016), Peradaban pada abad ke-21 sekarang ini banyak hal lebih didominasi dengan ilmu pengentahuan (khususnya sains) yang kemudian secara praksisi menjadi teknologi (Irwansyah, 2021). Maju atau mundurnya masyarakat di masa kini dan mendatang banyak dipengaruhi oleh penguasaan dan kemajuan sains. Dengan demikian tantangan bagi masyarakat muslim di bagian dunia manapun khususnya Indonesia terhadap sains dan teknologi menjadi tidak mudah lagi.

Namun seiring berkembangnya Perguruan Tinggi Islam dari tahun 1950 sampai dengan sekarang, menunjukkan bahwa dunia pendidikan tinggi Islam, sebagian besar masih mengikuti platform keilmuan klasik yang didominasi alulum al-syar"i. Kritik terhadap pola pengembangan ilmu-ilmu keislaman ini terutama di perguruan tinggi Islam belakangan mendapat perhatian lebih. Karena selama ini ilmu-ilmu keislaman yang berkembang hanya bersifat fragmenteris dan belum memiliki keterkaitan dengan isu-isu kekinian, memasuki periode modern, tradisi ini mengalami kesenjangan dengan perkembangan Ilmu Pengetahuan dan Tekologi. Menurut (Rahim, 2004) kesenjangan tersebut telah menghadapkan dunia pendidikan Islam pada tiga situasi yang buruk. Pertama, dikotomi yang berkepanjangan antara ilmu agama dan ilmu umum; Kedua, keterasingan pengajaran ilmu-ilmu keagamaan dari relalitas kemodernan; Ketiga, menjauhnya ilmu pengetahuan dari nilai-nilai agama. Oleh karena itulah diperlukan upaya membagun epistimologi keilmuan integratif-interkonektif.

Meski begitu integrasi juga membutuhkan sarana yag memungkinkan untuk terwujud dalam kehidupan akademisi secara nyata. Untuk kegiatan di PTAIN, Islamic Studies (Studi Islam) dirasa mampu mewujudkan misi dan tujuan integrasi. Oleh karena itu, berdasarkan latar belakang diatas, penulis merasa paradigma integratif-interkonektif dalam pendidikan Islam harus dikembangkan dan dibahas lebih lanjut.

\section{METODE PENELITIAN}

Sesuai dengan karakteristik masalah yang diangkat dalam penelitan ini maka menggunakan Metode Riset kualitatif, yaitu menekankan analisanya pada data deskriptif berupa kata-kata tertulis yang diamati. Pendekatan kualitatif penulis gunakan untuk menganalisis kajian jaring laba-laba, interaksi-interkoneksi Universitas Islam Negeri Sunan Kalidjaga Yogyakarta, maka dengan sendirinya penganalisaan data ini lebih difokuskan pada Penelitian Kepustakaan (Library Research), yakni dengan membaca, menelaah dan mengkaji buku-buku dan sumber tulisan yang erat kaitannya dengan masalah yang dibahas. Metode yang digunakan dalam kajian ini menggunakan metode atau pendekatan kepustakaan (library research), menurut Zed dalam (Rahayu, 2020) bahwa studi pustaka atau kepustakaan dapat diartikan sebagai serangkaian kegiatan yang berkenaan dengan metode pengumpulan data pustaka, membaca dan mencatat serta mengolah bahan penelitian.

Jenis penelitian ini adalah penelitian kualitatif. Menurut Ibnu dalam (Nasser, 2021) penelitian kualitatif adalah suatu penelitian yang datanya dinyatakan dalam bentuk verbal dan dianalisis tanpa menggunakan teknik statistik. Berdasarkan beberapa definisi penelitian kualitatif di atas, dapat disimpulkan bahwa penelitian kualitatif adalah suatu penelitian yang datanya dinyatakan dalam bentuk verbal, tidak menggunakan angka dan analisisnya tanpa menggunakan teknik statistik.

1. Objek Penelitian

Dalam penelitian ini objek penelitian terdiri dari 2 (dua), yaitu objek formal dan objek material (Arifudin, 2020). Objek formal dalam penelitian ini berupa data yaitu data yang berhubungan dengan tinjauan kritis jaring laba-laba, interaksi-interkoneksi Universitas Islam Negeri Sunan Kalidjaga Yogyakarta. Sedangkan objek materialnya berupa sumber data, dalam hal ini adalah tinjauan kritis terhadap jaring laba-laba, interaksi-interkoneksi Universitas Islam Negeri Sunan Kalidjaga Yogyakarta.

2. Waktu Penelitian

Penelitian ini dilaksanakan pada bulan Oktober sampai dengan Desember tahun 2021.

3. Teknik Pengumpulan Data

Pengumpulan data yang dilakukan dengan menggunakan teknik dokumentasi yaitu mengadakan survey bahan kepustakaan untuk mengumpulkan bahan-bahan, dan studi liter- 
atur yakni mempelajari bahan-bahan yang berkaitan dengan objek penelitian. Teknik pengumpulan data menurut (Bahri, 2021) mengemukakan bahwa merupakan langkah yang paling strategis dalam penelitian karena tujuan untama dari penelitian adalah mendapatkan data. Terdapat beberapa cara atau teknik dalam mengumpulkan data, diantaranya adalah observasi dan dokumentasi. Sumber data yang digunakan dalam penelitian ini mencakup data primer dan sekunder. Menurut (Hanafiah, 2021) bahwa data primer adalah data yang dikumpulkan langsung dari individu-individu yang diselidiki atau data tangan pertama. Sedangkan data sekunder adalah data yang ada dalam pustaka-pustaka. Data primer dalam penelitian ini adalah bukubuku terkait tinjauan kritis terhadap jaring laba-laba, interaksi-interkoneksi Universitas Islam Negeri Sunan Kalidjaga Yogyakarta, dan data sekunder didapatkan dari jurnal-jurnal baik nasional maupun internasional.

4. Alat Pengumpulan Data

Dalam penelitian ini, penulis akan menggunakan metode dokumentasi sebagai alat untuk pengumpul data karena penelitian ini adalah penelitian kepustakaan. Dengan kata lain, menurut (Juhji, 2020) bahwa teknik ini digunakan untuk menghimpun data-data dari sumber primer maupun sekunder.

5. Teknik Analisis Data

Analisis data tidak saja dilakukan setelah data terkumpul, tetapi sejak tahap pengumpulan data proses analisis telah dilakukan. Penulis menggunakan strategi analisis "kualitatif", strategi ini dimaksudkan bahwa analisis bertolak dari data-data dan bermuara pada kesimpulan-kesimpulan umum. Berdasarkan pada strategi analisis data ini, dalam rangka membentuk kesimpulan-kesimpulan umum analisis dapat dilakukan menggunakan kerangka pikir "induktif". Menurut (Sugiyono, 2015) bahwa metode pembahasan menggunakan metode deskriptif-analisis, yaitu menjelaskan serta mengelaborasi ide-ide utama yang berkenaan dengan topik yang dibahas. Kemudian menyajikannya secara kritis melalui sumber-sumber pustaka primer maupun skunder yang berkaitan dengan tema.

6. Prosedur Penelitian

Data pada penelitian ini dicatat, dipilih dan kemudian diklasifikasikan sesuai dengan kategori yang ada. Pendekatan yang digunakan adalah pendekatan deskriptif analitis. Menurut (Arifudin, 2019) bahwa deskriptif analitis (descriptive of analyze research), yaitu pencarian berupa fakta, hasil dari ide pemikiran seseorang melalui cara mencari, menganalisis, membuat interpretasi serta melakukan generalisasi terhadap hasil penelitian yang dilakukan. Prosedur penelitian ini adalah untuk menghasilkan data deskriptif yang berupa data tertulis setelah melakukan anaisis pemikiran (content analyze) dari suatu teks. Setelah penulis mengumpulkan bahanbahan yang berhubungan dengan masalah yang akan di bahas dalam penelitian ini, kemudian penulis menganalisis dan menarasikan untuk diambil kesimpulan.

\section{HASIL DAN PEMBAHASAN}

Dalam pembahasan ini akan dibahas tentang Pengertian Pendekatan Interdisipliner: Integratif -Interkonektif, Paradigma Integratif-Interkonektif Menurut Amin Abdullah, dan Implementasi Paradigma Integratif-Interkonektif dalam Studi Islam.

1. Pengertian Pendekatan Interdisipliner: Integratif-Interkonektif

Interdisipliner yaitu kerjasama antar satu ilmu dengan ilmu lain sehingga menjadi satu kesatuan dengan metode sendiri. Menurut definisi lain Interdisipliner (interdisciplinary) adalah interaksi intensif antar satu atau lebih disiplin, baik yang langsung berhubungan maupun tidak, melalui program-program pengajaran dan penelitian, dengan tujuan melakukan integrasi konsep, metode, dan analisis, sedangkan definisi pendekatan Interdisipliner yaitu suatu pendekatan dalam pemecahan suatu masalah dengan menggunakan tinjauan berbagai sudut pandang ilmu serumpun yang relevan atau tepat guna secara terpadu. Kajian interdisipliner sejalan dengan kenyataan bahwa ilmu pengetahuan berkembang menjadi sintesis dari dua bidang ilmu pengetahuan yang berbeda, dan berkembang menjadi satu disiplin ilmu tersendiri. Contoh sebuah ilmu linguistik membutuhkan ilmu psikologi maka munculah ilmu psikologi linguistik. Integratif-Interkonektif sendiri didasarkan pada paradigma agama dan sains integratif-interkonektif atau paradigma kesatuan dan terpadu/non dikotomik antara agama dan sains. Dan untuk mewujudkannya dilakukan dengan memposisikan dan menghubungkan agama dan sains secara tegas dan jelas (Al-Makin, 2017). 
2. Paradigma Integratif - Interkonektif Menurut Amin Abdullah

M. Amin Abdullah lahir di Margomulyo, Tayu, Pati Jawa Tengah pada tanggal 28 Juli 1953. Pada tanggal 13 Mei 2000 beliau diangkat menjadi Guru besar Filsafat Islam di UIN Sunan Kalijaga, dan semenjak tahun 2001 sampai 2010 beliau menjabat sebagai Rektor UIN Sunan Kalijaga. Beliau merupakan pemikir prolifik dalam gelanggang cendekiawan Muslim Indonesia. Beliau tidak hanya mampu mensintesiskan diantara sekian banyak argumen yang bertentangan, tetapi juga mampu melahirkan sebuah konsep cerdas dan akomodatif dan dapat menjadi jawaban atas permasalahan yang muncul (Riyanto, 2013), Istilah paradigma pertama kali dikemukakan oleh Thomas S. Kuhn dalam The Structure of Scientific Revolution. Kuhn mendefinisikan paradigma sebagai pandangan hidup (world-view atau weltanschauung) yang dimiliki oleh ilmuwan dalam suatu disiplin tertentu. Sedang Robert A.Friedrichs dalam Sociology of sociology mendefinisikan paradegma sebagai suatu gambaran yang mendasar mengenai pokok permasalahan yang dipelajari dalam suatu disiplin (Tobroni, 2003). Dan Muslih mengibaratkan paradigma sebagai sebuah jendela tempat orang mengamati dunia luar, tempat orang bertolak menjelajahi dunia dengan wawasannya (world-view) (Muslih, 2014).

Kenyataan bahwa ada sebagian masyarakat yang memahami secara kurang tepat hubungan antara ilmu-ilmu agama dan ilmuilmu pengetahuan. Serta ditambah lagi kebijakan pendidikan dari pemerintah yang dikotomik, menjadi salah satu alasan Amin Abdullah untuk meluruskan, membenahi, mendobrak pemahaman tersebut melalui buku Islamic Studies: Pendekatan Integratif-Interkonektif.

Ide tersebut bertujuan untuk memahami kompleksitas fenomena kehidupan yang dihadapi dan dijalani manusia tidak bisa bersifat single entity. Masing-masing harus saling berkesinambungan dengan yang lain. Kerjasama, saling membutuhkan, saling koreksi, dan keterhubungan antara disiplin keilmuan akan lebih dapat membantu manusia memahami problematika kehidupan (Bairizki, 2021).

Adanya dikotomik yang cukup tajam antara ilmu sekuler dan ilmu agama ini membuat keduanya seolah mempunyai wilayah yang terpisah antara satu sama lain. Ilmu-ilmu sekuler dikembangkan di perguruan tinggi umum dan ilmu-ilmu tersebut berjalan seolah tercabut dari nilai-nilai moral dan etis kehidupan manusia. Sementara itu ilmu-ilmu agama dikembangkan di perguruan tinggi agama yang hanya menekankan pada teksteks Islam normatif, sehingga dirasa kurang menjawab tantangan zaman. Jarak yang cukup jauh ini kemudian menjadikan kedua bidang keilmuan ini mengalami proses pertumbuhan yang tidak sehat serta membawa dampak negatif bagi pertumbuhan dan perkembangan kehidupan sosial, budaya, ekonomi, politik, dan keagamaan Indonesia (Amin, 2010).

Paradigma Integratif-Interkonektif yang ditawarkan Amin Abdullah merupakan jawaban dari berbagai persoalan tersebut. Dengan paradigma ini maka tiga wilayah pokok dalam ilmu pengetahuan yakni natural sciences, sosial sciences, dan humanities tidak lagi berdiri sendiri tetapi akan saling terkait satu sama lain (Amin, 2010), Hadrarah al-ilm (peradaban ilmu) yatu ilmu-ilmu empiris seperti sains, teknologi, dan ilmu-ilmu yang terkait dengan realitas tidak lagi berdiri sendiri tetapi juga bersentuhan dengan hadarah al-falsafah (peradaban filsafat). Begitu juga sebaliknya hadarah al-falsafah akan terasa kering dan gersang jika tidak terkait dengan isu-isu keagamaan yang termuat dalam budaya teks (hadarah al-nash) dan lebih-lebih jika menjauh dari problemproblem yang ditimbulkan dan dihadapi oleh hadarah al-ilm. Dari hadarah tersebut melahirka pola single entity, isolated entities, dan interconnected (Amin, 2010).

Paradigma integrasi-interkoneksi ini terlihat sangat dipengaruhi oleh Muhammad Abid al-Jabiri yang membagi epistemologi Islam menjadi tiga, yaitu epistemologi bayani, epistemologi burhani, dan epistemologi 'irfani. Berbeda dengan al-Jabiri yang melihat epistemologi 'irfani tidak penting dalam perkembagan pemikiran Islam. Sedangkan menurut Amin Abdullah ketiga epistemologi tersebut seharusnya bisa berjalan beriringan. Selama ini epistemologi bayani lebih banyak mendominasi dan bersifat hegemonik sehingga sulit untuk berdialog dengan tradisi epistemologi irfani dan burhani, pola pikir bayani ini akan berkembang jika melakukan dialog, mampu memahami dan menambil manfaat sisi-sisi fundamental yang dimiliki oleh pola pikir irfani dan burhani (Amin, 2002). 
Hubungan atara ketiga epistemologi ilmu tersebut pun tidak dalam bentuk pararel atau linier, melainkan dalam bentuk sirkular. Bentuk pararel akan melahirkan corak epistemologi yang berjalan sendiri-sendiri tanpa adanya hubungan dan persentuhan antara satu dengan yang lain.

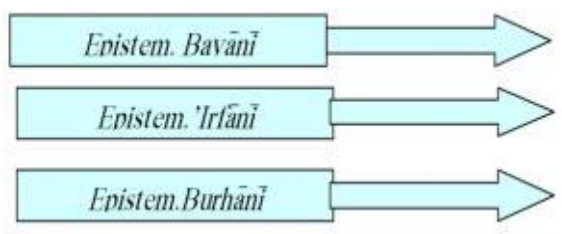

Gambar 1. Epistemologi Ilmu Pararel

Sedangkan bentuk linier akan berasumsi bahwa salah satu dari tiga epistemologi menjadi "primadona" sehingga sangat tergantung pada latar belakang, kecenderungan dan kepentingan pribadi atau kelompok.

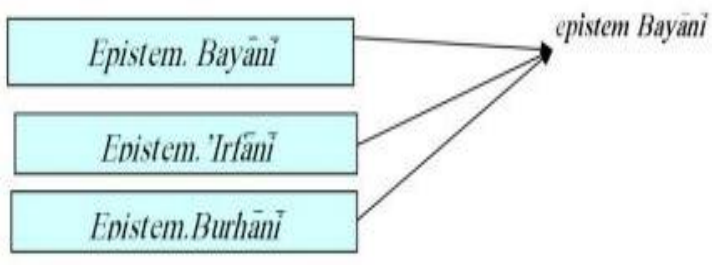

Gambar 2. Epistemologi Ilmu Linier

Sedangkan dengan bentuk srikular diharapkan masing-masing corak epistemologi keilmuan dalam Islam akan memahami kekurangan dan kelebihan masing-masing dan dapat mengambil manfaat dari temuantemuan yang ditawarkan oleh tradisi keilmuan lain dalam rangka memperbaiki kekurangan yang ada (Amin, 2010).

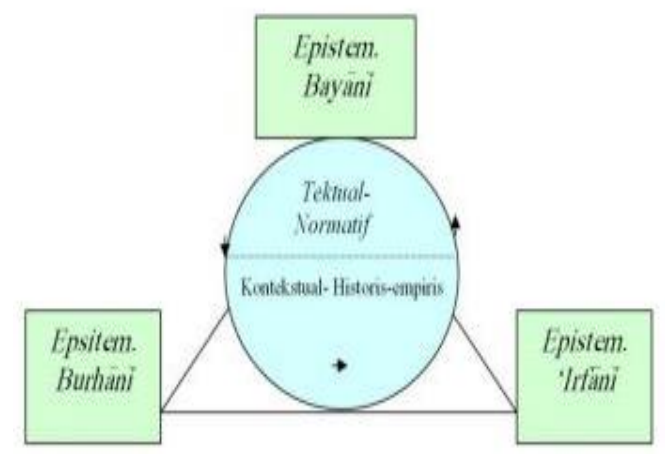

Gambar 3. Epistemologi Ilmu Srikular

Berbeda dengan kampus lain, jargon integratif-interkonektif sudah cukup populer didengar bagi kalangan civitas akademika Universitas Islam Negeri Sunan Kalijaga
Yogyakarta. Integratif-Interkonektif ini sendiri pun menjadi core values dan paradigma yang dikembangkan UIN Sunan Kalijaga yang mengisyaratkan tidak ada lagi dikotomi antara ilmu agama dan umum, pola hubungan srikular inilah yang dijadikan sebagai grand desain payung keilmuan UIN Sunan Kalijaga, yang dikenal dengan jaring laba-laba keilmuan.

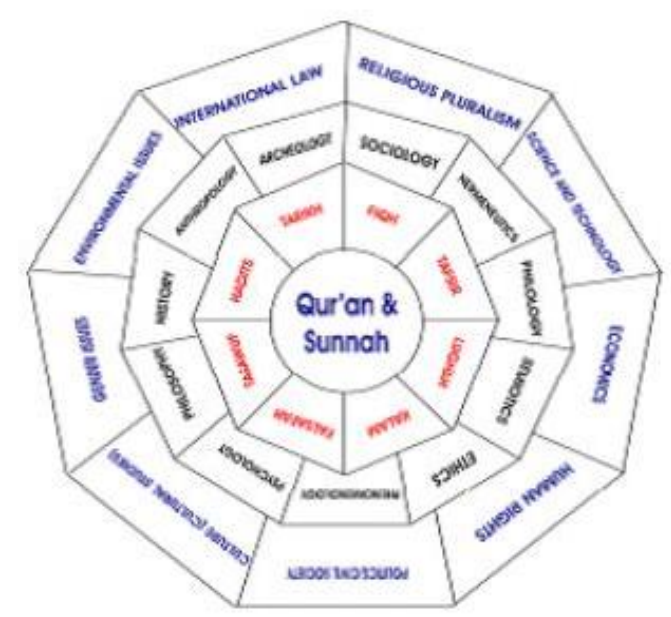

Gambar 4. Grand Desain Payung Keilmuan UIN Sunan Kalijaga.

Gambar tersebut menjelaskan bahwa sumber dari segala ilmu itu adalah nash al-Qur'an atau kalamullah dan alam semesta (hukum alam) sunatullah. Sehingga semua ilmu pengetahuan yang tertulis dalam gambar jaring laba-laba diatas digali dan di kembangkan dari dua sumber kalamullah dan sunatullah tersebut. Nampak jelas keterhubungan satu dengan yang lainnya. Garis-garis yang membatasi satu pengetahuan menunjukkan adanya pintu yang terbuka untuk saling menerima pengetahuan lainnya (Al-Makin, 2017).

Dari pemaparan diatas dapat disimpulkan bahwa paradigma integrasi-interkoneksi ini merupakan jawaban atau respon terhadap kesulitan-kesulitan selama ini karena terpisahnya ilmu umum dan ilmu agama. Dari paradigma tersebut dapat kita pahami bahwa setiap bangunan keilmuan apapun, baik ilmu agama, sosial, humaniora, kealaman, psikologi dan lain sebagainya tidak bisa bersifat single entity. Masing-masing dari ilmu tersebut saling membutuhkan satu sama lain yang dapat membantu manusia dalam memahami kompleksitas kehidupan dan memecahkan persoalan yang ada. 
3. Implementasi Paradigma Integratif-Interkonektif dalam Studi Islam

Paradigma Integrasi-Interkoneksi sebagai paradigma baru hasil revolusi keilmuan yang merupakan landasan kerja keilmuan Perguruan Tinggi Islam yang mendasarkan kajian mencakup seluruh bidang keilmuan yang dikemangkan melalui konsep hadarah al-nash (ilmu-ilmu yang berkatan dengan teks keagamaan), hadarah al-ilm (ilmu-ilmu kealaman dan kemasyarakatan), dan hadarah alfalsafah (ilmu-ilmu etika kefilsafatan).

Fungsi paradigma adalah memberikan kerangka, mengarahkan, dan menguji consistensi dari proses keilmuan (Hasbi, 2021). Paradigma merupakan kerangka logis dari teori sehingga satu paradigma bisa melingkupi beberapa teori meskipun paradigma lahir dari akumulasi teori-teori yang saling mendukung dan saling menyempurnakan serta enjadi satu kebutuhan dan sebuah konsisten yang utuh, sebaliknya dari suatu paradigma ilmu dapat dilahirkan teori-teori baru berdasarkan temuan-temuan para ilmuwan. Suatu paradigma digunakan atau dpilih tidak berdasarkan salah atau benarnya sebagai suatu sudut padang terhadap sesuatu tetapi apakah sudut pandang itu lebih bermanfaat atau kurang bermanfaat .

Sebagai paradigma alternatif dalam studi ke-Islaman, paradigma Integrasi-Interkoneksi memberikan beberapa landasan kerja yang khas dalam melakukan pembaharuan, disamping prinsip umum integrasi-interkoneksi. Sebagai contoh, jika secara umum pengembangan kurikulum didasarkan atas landasan filosofis, sosiologis, organisatoris, psikologis, dan landasan sosial budaya. Maka paradigma integrasi-interkoneksi ilmu ke-Islaman, disamping menggunakan landasan-landasan tersebut, menekankan adanya landasan teologis sebagai landasan pokok.

Implementasi paradigma Integrasi-Interkoneksi dikembangkan dengan prinsip yang fleksibel, hal tersebut disebabkan keragaman jenis keilmuan. Prinsip fleksibilitas tersebut diwujudkan dalam beberapa level yang pernah disosialisasikanndi UIN Sunan Kalijaga Yogyakarta baik untuk dosen dan mahasiswa meliputi : 1) Level filosofis 2) Level materi 3) Level metodologi 4) Level strategi. Sedangkan dalam kajian keilmuan, paradigma IntegrasiInterkoneksi bisa dilakukan dengan beberapa model yaitu: 1) Model informatif 2) Model konfirmatif-klarifikatif 3) Model korektif 4)
Model similarisasi 5) Model paralelisasi 6) Model komplementasi 7) Model komparasi 8) Model induktifikasi, dan 9) Model verifikasi (UIN Sunan Kalijaga, 2006).

Adapun Implementasi integrasi-interkoneksi di UIN Sunan Kalijaga tampak dan beroperasi dalam hal-hal berikut: 1) Rencana Induk Pengembangan (RIP) 2) Rencana strategis (Renstra) dan Rencana Kerja Tahunan (RKT) 3) Kurikulum (berbasis KKNI sesuai SN Dikti, Silabus dan RPS) 4) Pedoman Akademik 5) Layanan Akademik 6) Penelitian 7) Pengabdian Kepada Masyarakat 8) Struktur kelembagaan 9) Kepegawaian 10) Perencanaan 11) Keuangan 12) Layanan Administrasi Umum 13) Sarana dan Prasarana 14) Kemahasiswaan dan Alumni 15) Kerja sama 16) Layanan penjamin mutu 17) Layanan digital 18) Perpustakaan 19) Layanan Difabel 20) Pengembangan Agama, Budaya, dan Bahasa 21) Laboratorium Agama 22) Laboratorium sains (Al-Makin, 2017).

\section{SIMPULAN DAN SARAN}

\section{A. Simpulan}

Berdasarkan pemaparan pada penelitian ini dapat disimpulkan bahwa pendekatan Interdisipliner yaitu suatu pendekatan dalam pemecahan suatu masalah dengan menggunakan tinjauan berbagai sudut pandang ilmu serumpun yang relevan atau tepat guna secara terpadu. Integratif-Interkonektif sendiri didasarkan pada paradigma agama dan sains integratif-interkonektif atau paradigma kesatuan dan terpadu/non dikotomik antara agama dan sains. Dan untuk mewujudkannya dilakukan dengan memposisikan dan menghubungkan agama dan sains secara tegas dan jelas. Paradigma integrasi-interkoneksi ini merupakan jawaban atau respon terhadap kesulitan-kesulitan selama ini, karena terpisahnya ilmu umum dan imu agama. Dari paradigma tersebut dapat kita pahami bahwa setiap bangunan keilmuan apapun, bak ilmu agama, sosial, humaniora, kealaman, psikologi dan lain sebagainya tidak bisa bersifat single entity. Masing-masing dari ilmu tersebut saling membutuhkan satu sama lain yang dapat membantu manusia dalam memahami kompleksitas kehidupan dan memecahkan persoalan yang ada. Fungsi paradigma adalah memberikan kerangka, mengarahkan, dan menguji konsistensi dari proses keilmuan. Paradigma merupakan kerangka logis dari teori sehingga satu paradigma bisa melin- 
gkupi beberapa teori meskipun paradigma lahir dari akumulasi teori-teori yang saling mendukung dan saling menyempurnakan serta menjadi satu kebutuhan dan sebuah konsisten yang utuh, sebaliknya dari suatu paradigma ilmu dapat dilahirkan teori-teori baru berdasarkan temuan-temuan para ilmuwan.

\section{B. Saran}

Pembahasan terkait penelitian jaring labalaba, interaksi-interkoneksi Universitas Islam Negeri Sunan Kalidjaga Yogyakarta dalam penelitian ini masih sangat terbatas dan membutuhkan banyak masukan. Saran untuk penulis selanjutnya adalah mengkaji lebih dalam dan secara komprehensif terkait jaring laba-laba, interaksi-interkoneksi Universitas Islam Negeri Sunan Kalidjaga Yogyakarta.

\section{DAFTAR RUJUKAN}

Al-Makin. (2017). Sosialisasi Pembelajaran Menjadi Mahasiswa Visioner di UIN Sunan Kalijaga. Yogyakarta: UIN Sunan Kalijaga.

Amin. (2002). Tafsir Baru Studi Islam dalam Era Multikultural. Yogyakarta: Panitia Dies IAIN Sunan Kalijaga Yogyakarta ke 50 dan Kurnia Alam Semesta.

Amin. (2010). Islamic Studies di Perguruan Tinggi: Pendekatan Integratif-Interkonektif . Yogyakarta: Pustaka Pelajar.

Arifudin, O. (2019). Manajemen Sistem Penjaminan Mutu Internal (SPMI) Sebagai Upaya Meningkatkan Mutu Perguruan Tinggi. MEA (Manajemen, Ekonomi, \& Akuntansi), 3(1), 161-169.

Arifudin, O. (2020). Manajemen Risiko. Bandung : Widina Bhakti Persada.

Arifudin, 0. (2021). Implementasi Balanced Scorecard dalam Mewujudkan Pendidikan Tinggi World Class. Edumaspul: Jurnal Pendidikan, 5(2), 767-775.

Asmedy, A. (2021). Perbandingan Hasil Belajar Matematika Siswa yang diajar dengan Model Pembelajaran Possing Problem Berkelompok dan Metode Ceramah. Jurnal Inovasi, Evaluasi Dan Pengembangan Pembelajaran (JIEPP), 1(2), 69-75. https://doi.org/10.54371/jiepp.v1i2.107
Bahri, A. S. (2021). Pengantar Penelitian Pendidikan (Sebuah Tinjauan Teori dan Praktis). Bandung : Widina Bhakti Persada.

Bairizki, A. (2021). Manajemen Perubahan. Bandung : Widina Bhakti Persada.

Hanafiah, H. (2021). Pelatihan Software Mendeley Dalam Peningkatan Kualitas Artikel Ilmiah Bagi Mahasiswa. Jurnal Karya Abdi Masyarakat, 5(2), 213-220.

Hasbi, I. (2021). Administrasi Pendidikan (Tinjauan Teori Dan Praktik). Bandung: Widina Bhakti Persada.

Irwansyah, R. (2021). Perkembangan Peserta Didik. Bandung : Widina Bhakti Persada.

Juhji. (2020). Manajemen Humas Sekolah. Bandung: Widina Bhakti Persada.

Muslih. (2014). Pengantar Ilmu Filsafat. Ponorogo : Darussaam University Press.

Na'im, Z. (2021). Manajemen Pendidikan Islam. Bandung : Widina Bhakti Persada.

Nasser, A. A. (2021). Sistem Penerimaan Siswa Baru Berbasis Web Dalam Meningkatkan Mutu Siswa Di Era Pandemi. Biormatika: Jurnal Ilmiah Fakultas Keguruan Dan Ilmu Pendidikan, 7(1), 100-109.

Nasution. (2016). Pengantar Studi Islam Dilengkapi Pendekatan IntegratifInterkonektif (Multidisipliner). Jakarta: PT. Raja Grafindo Persada.

Nurhasanah, E. (2021). Peran Orang tua dalam Membimbing Anak Usia Sekolah Dasar di Rumah pada Masa Pandemi Covid-19. Jurnal Inovasi, Evaluasi Dan Pengembangan Pembelajaran (JIEPP), 1(1), 11-18. https://doi.org/10.54371/jiepp.v1i1.75

Rahayu, Y. N. (2020). Program Linier (Teori Dan Aplikasi). Bandung : Widina Bhakti Persada.

Rahim. (2004). Horizon Baru Pengembangan Pendidikan Islam. Malang: UIN Malang Press. 
Riyanto. (2013). Integrasi-Interkoneksi Keilmuan; Biografi Intelektual M. Amin Abdullah (1953...) Person, Knowledge, and Institution. Yogyakarta: SUKA Press.

Tobroni. (2003). Metodologi Penelitian Sosial Agama. Bandung: Remaja Rosdakarya.
UIN Sunan Kalijaga. (2006). Kerangka Dasar Keilmuan dan Pengembangan Kurikulum UIN Sunan Kalijaga. Yogyakarta: Pokja Akademik UIN. 